\title{
Preventing Youth from Driving High
}

\author{
Jessica Lee Anna Davis and Magdalena Cismaru
}

\begin{abstract}
This paper investigates best theories and practices in the context of youth drug driving and describes initiatives aiming to decrease the incidence of youth driving high. Secondary data searches and content analysis of existent campaigns is conducted. Findings show that most initiatives properly use fear tactics and attempt to make youth feel that the issue is severe and that they are vulnerable to the negative consequences of driving high. Initiatives can become more effective if they provide specific and easy-to-follow recommendations of how to abstain from driving high, help young people abstain from driving high, make them feel that they can abstain from driving high, and showing how following the recommendations would succeed in preventing accidents. Implications and suggestions are discussed.
\end{abstract}

Keywords: youth, impaired driving, drugs, marijuana, Extended Parallel Process Model

Jessica Davis is a recent MBA graduate from the University of Regina's Kenneth Levene Graduate School of Business. She works in the insurance industry as a market research analyst. Her research interests include social marketing, particularly in the areas of impaired driving and youth health communications. Mailing address is: 2217 Pasqua Street, Regina, Saskatchewan, S4T 4M5, Canada; Email address: davis26j@uregina.ca

Magdalena Cismaru, Ph.D., is a professor and Conexus research scholar in financial well-being in the Faculty of Business Administration at the University of Regina. Her research in the area of social marketing and health decision making has been published widely in a variety of journals including Journal of Social Marketing, Young Consumers, Marketing Theory, Journal of Advertising, Social Marketing Quarterly, International Marketing Review, International Review on Public and Nonprofit Marketing, and Canadian Public Policy. Mailing address is: University of Regina, Faculty of Business Administration, 3737 Wascana Parkway, Regina, Saskatchewan, S4S 0A2, Canada; E-mail address: Magdalena.Cismaru@uregina.ca 


\section{Introduction}

Marijuana (also known as cannabis, weed, pot, dope, or grass) is the most commonly used illicit drug globally (United Nations Office on Drugs and Crime, UNODC, 2015). Medical cannabis is legal in many countries including more than 30 states in the United States of America (USA) (Berke and Gould, 2018; Forrest, 2017). As well, it is legal in seven states in the USA for recreational use and in all Canadian provinces for both recreational and medical use (Berke and Gould, 2018; Forrest, 2017). Studies show that where there is marijuana legalization, the number of accidents and fatalities have increased (Migoya, 2017). Indeed, marijuana is the leading drug to cause deaths in roadside accidents in Canada. In 2014, 27\% of all Canadian highway crashes resulting in death involved drugs alone; of these 618 deaths, nearly half of the drivers causing death tested positive for marijuana (Mothers against Drunk Driving, MADD, 2018a).

Due to marijuana's legalization and its negative consequences on driving, initiatives have been developed aiming at preventing driving under the influence of marijuana. However, most initiatives are not based on academic research, do not use a theory-based approach, and do not report any evaluation, making it difficult to assess their effectiveness and influence on behavioral change (Manikam and Russell-Bennett, 2016). Evaluative studies have been conducted for reviewing similar campaigns preventing dangerous or risky behaviours in respect to driving. For instance, Cismaru (2014) reviewed campaigns preventing texting and driving, showed how they often lacked an evaluative approach to examine their effectiveness, and used a theoretical approach to evaluate them and provide recommendations to improve their effectiveness. Indeed, approaches that aim to learn from previous campaign efforts can yield valuable insights and lead to recommendations to improve the effectiveness of future initiatives (Manikam and Russell-Bennett, 2016).

Consequently, this study has the following objectives:

- Review the literature regarding marijuana consumption and knowledge related to young people driving under the influence of cannabis;

- Identify appropriate theoretical frameworks and literature that can guide the development of effective social marketing campaigns in the context of youth driving high;

- Identify, review and analyse existing initiatives against youth driving under the influence of drugs such as marijuana; and

- Propose recommendations to improve the effectiveness of efforts aiming to prevent young people from driving high.

\section{Literature Review}

Marijuana Consumption

MacDonald and Rotermann (2017) tracked cannabis consumption longitudinally from 1970 to 2015 in order to identify marijuana usage trends across different lifecycles. They estimated the annual value of recreational cannabis use in Canada at $\$ 6.2$ billion dollars. It was identified 
that marijuana usage was most prevalent for young people and least prevalent for adults, consecutively, for each period of time. Indeed, Canadian young consumers are the top users of marijuana in the developed world (Bojkovsky et al., 2017; McKiernan and Fleming, 2017). The percentage of youth $(22 \%)$ and young adults $(26 \%)$ who used marijuana in 2013 was more than two and a half times that of adults 25 and older (8\%) (MacDonald and Rotermann, 2017). Worth noting is that consumption of marijuana was illegal during this time period in Canada. Even so, this trend demonstrates that individual marijuana usage is common among youth and young adults. For this reason, this paper focuses on drivers younger than 25 years age.

\section{Factors Contributing to Marijuana Consumption among Young People}

Youth report using marijuana for its benefits, including experiencing a relaxed state, heightened sense of euphoria and intense laughter, and increased sociability (Hall \& Degenhart, 2009). They believe that using marijuana reduces stress and they can easily purchase it due to increased accessibility (McKiernan \& Fleming, 2017). In addition, studies indicate that drug use is associated with peer influence and group attractiveness. Indeed, the more attractive the individual perceives illicit drug consumption to be, the more likely they are to give in to peer pressure in each situation (Rose et al., 2001). Research shows today's youth see marijuana as safe, believing it is a plant with minimal harmful attributes, aiding in their justification of experimentation (Bojkovsky et al., 2017).

One source of these pro-use perceptions may include advertising that has escalated the belief that marijuana is safe for youth and young adults to consume. MedMen, a large company in the marijuana market, recently launched a pro-marijuana campaign in California, where marijuana was legalized in January 2018. The campaign features the slogans, "Relax. It's legal." and "Heal. It's legal." The campaign glorifies marijuana for its benefits and shows faces of young people smoking marijuana (Handley, 2018). In countries where marijuana use is legalized, such as Canada and some parts of the USA, studies indicate that individuals show strong recall for marijuana advertising and promotions (Fiala et al., 2018). Despite the perceived benefits promoted by prouse campaigns, the risks associated with marijuana's use are serious but not recognized by many youth.

Youth and Driving Under the Influence of Cannabis

Significant evidence shows that driving high leads to a higher rate of road accidents and puts the public at greater risk on the road (Bojkovsky et al., 2017). Indeed, between 2000 and 2007, 12,978 drivers were killed in vehicle crashes on public roads only in Canada. Of these, $46.4 \%(6,016)$ tested positive for drugs other than alcohol, and cannabis was the leading category of substances detected (MADD, 2018a). Studies show that the incidence of driving under the influence of cannabis (DUIC) has surpassed the incidence of driving under the influence of alcohol (DUIA) in Canada (University of Victoria, 2014). Making matters worse, cannabis crashes were more likely to involve multiple vehicles than crashes involving only alcohol (Hall, 2009). 
Driving under the influence of marijuana increases the risk of accidents by decreasing attention spans, slowing reaction times and impairing the driver's ability to respond to a sudden traffic event (MADD, 2018b). Driving within 90 minutes of using marijuana causes the driver to have the inability to use cautionary compensative driving behavior. This leads to the inability to track speed adjustments, maintain consistent lane position, and perform routine automatic driving processes (Turnbull \& Hodge, 2017; University of Victoria, 2014). Smoking cannabis three hours before driving nearly doubles the driver's risk of a motor vehicle crash (Asbridge et al., 2012). For this reason, driving under the influence of marijuana remains illegal even in jurisdictions where recreational consumption has been legalized.

Driving under the influence of marijuana remains normalized in society and incidence of youth driving high is on the rise. Research shows that one in four cannabis users have driven while high (Bojkovsky et al. 2017; MADD, 2018b). Driving high is most prevalent in drivers under the age of 24, even more prevalent than drinking and driving (MADD, 2018b; Maxwell, 2012; University of Victoria, 2014). The most likely segment to drive high is young, single males. These males tend to use cannabis frequently, have an early initiation to cannabis and report using additional illicit drugs. These individuals are more likely to drive after drinking and to operate a vehicle within two hours of using cannabis (University of Victoria, 2014).

\section{Young Consumer Perceptions on Driving High}

Young consumer perceptions do not match the severity in statistics about driving high. In $2014,26.9 \%$ of roadside deaths involved those that were drug driving, while another $14.5 \%$ involved those that drove high and drunk (MADD, 2018a). Despite the number of reported deaths due to driving high, $63 \%$ consumers between the ages of 18-29 felt that marijuana legalization in certain states would not have any effect on the safety of the roads (YOURS News, 2015).

One study indicated that the lack of awareness of the dangers of cannabis driving among youth could be due to the limited exposure to first-hand accounts of accidents that were attributed solely to cannabis use, especially regarding death (McKiernan \& Fleming, 2017). The participants in this study reported growing up hearing about accidents involving alcohol related crashes, but not as many involving cannabis: "You hear about all these tragic car accidents and they never say marijuana or drug use. It's always like, alcohol. People are stupider when they get drunk" (McKiernan \& Fleming, 2017). In this study, youth were aware that there are similar penalties for drug driving as there are for drunk driving, but they believed that those who drive high are less likely to be apprehended due to a lack of their peers being caught doing so.

Several other studies show that youth perceive a lack of consequences when it comes to driving under the influence of marijuana (McKiernan \& Fleming, 2017). While those that do not drive high see drug driving as an action with serious consequences, $44 \%$ of those that drive high stated that it does not affect their ability to drive safely (StateFarm, 2017). One participant mentioned that roadside safety only depended on level of marijuana consumption: "I think it depends on how high you are. If you're out-of-your-mind high, then yeah, you shouldn't be driving, but I mean, if you're just like, pretty much sober and maybe you just had a toke, then I could drive absolutely fine." Another one voiced "Marijuana is the best, it completely mellows you out and you might be a bit paranoid, so you'll drive slower," whereas another mentioned "It's 
like your risk is great depending on what drug you're on. Like ice is crazy but if you smoke a bit of dope it's not that bad... it just depends on the person" (Barrie et al., 2011). Indeed, nearly one third of teenagers do not consider driving high to be as bad as driving under the influence of alcohol. Unfortunately, nearly $25 \%$ of teenagers' parents feel the same way (MADD, 2018b).

\section{Roadside Drug Detection}

The prevalence of driving high has been underestimated due to several challenges. First, it is difficult to accurately test for the presence of marijuana. While alcohol is water soluble and easily detected in roadside tests, marijuana contains fat soluble components THC, Carboxy and Hydroxy, which cannot be easily detected in a roadside test (Turnbull \& Hodge, 2017). Second, only the presence of THC or Hydroxy in one's blood may correlate with impairment. THC and Hydroxy levels in the blood tend to peak within 30 minutes and decrease rapidly over the course of four hours. In contrast, Carboxy can linger for days in the blood after a single use or light usage complicating the overall detection of marijuana in the user (Turnbull \& Hodge, 2017). Third, most driving under the influence of drugs (DUID) cases involve more than one drug, which makes it difficult to tell which drug caused impairment (Wood \& Salomonsen-Satuel, 2016). Finally, law enforcement officers do not test for drug impairment if the alcohol level is above the legal limit (Maxwell, 2012). These challenges all contribute to underestimating the prevalence of driving high.

There are two main reasons youth believe they will not be caught driving high. First, they believe their ability to drive will not be impacted by marijuana consumption and second, they largely believe there is no roadside test for driving high (MADD, 2018b). Contrary to public perception, there is a roadside test for marijuana consumption in countries such as Canada. The Drug Recognition Experts (DRE) use a 12-step process to determine if an individual is driving high, which will be upheld in court (Royal Canadian Mounted Police, 2018). With the legalization of marijuana, traffic enforcement has tightened road side testing, making it more likely someone driving under the influence of marijuana will be caught.

\section{Theoretical Frameworks for Effective Behavioral Change Campaigns}

In this study, as in Cismaru and Wuth (2019), two theoretical frameworks will be utilized to evaluate current social marketing campaign efforts to prevent young people from driving high and determine recommendations for future campaign creation. These frameworks are Noar's (2012) Audience-Channel-Message-Evaluation Framework (ACME) and Witte's (1992; 1998) Extended Parallel Process Model (EPPM). These two frameworks will be used complementarily. The ACME framework will be used to describe the essential components of a campaign, while the EPPM framework will describe the essential messaging components of an effective campaign (the "M" from the ACME framework). 
Audience-Channel-Message-Evaluation Framework (ACME) and its Implications on Drug Driving

Noar (2012) describes the ACME framework as a holistic approach to designing an effective campaign; one that goes beyond outcome evaluation. The framework presents a key set of principles demonstrating the relationships and linkages between four components: Audience, Channel, Message, and Evaluation. These four components must be addressed and continuously evaluated to improve the effectiveness of a campaign.

\section{Audience}

Noar (2012) describes the audience as the single most important decision that the developer has to make since a ripple effect occurs that leads to the choice of the appropriate channel and message(s) of the campaign. Noar (2012) states that a campaign can fail when the intended audience is either too broad or too narrow and a campaign that is designed for everyone will be successful with virtually no one. There comes a need for the identification of a homogeneous group or segmentation, in order to have the message resonate with the intended audience. An example of a relatively homogeneous group is young adults.

\section{Channel}

It is important to determine which channels will allow the social marketer to best reach their intended audience. Noar (2012) describes that this is interrelated with messaging and that different channels have varying degrees of access, reach and credibility. For example, hard hitting messages are more likely to be better suited for television as they are high in message sensation value. In addition, by using more channels to market to an audience, the marketer has an opportunity to build and strengthen the relationship between the organization and consumer, as well as get their intended message across (Kushwaha, 2007). Individuals using multiple channels are exposed to up to four times as much media than those who are only using one channel (Valos, 2008). Marketers are able to increase customer reach by applying a multi-channel marketing approach when targeting customers.

In order to appropriately target young adults, a social marketer must consider what channels they spend their time on most. For example, young adults prefer online radio and satellite radio over traditional radio (Werbner, 2005) and music streaming services such as Spotify and Apple Music. Spotify currently accounts for $36 \%$ of music streaming subscribers world-wide (Statista, 2018b). Today, young consumers have more channels than ever before to access information, as the majority carry a smart phone with endless search engine possibilities and inhouse application downloads (Werbner, 2005).

Other forms of traditional media have begun to decline among young individuals. Today youth are spending an average of 135 minutes per day on social media world-wide. This is a 45 minute increase from five years ago (Statista, 2018a). Studies indicate that social media is changing the business landscape and more than half of consumers are interacting with brands via social sites such as LinkedIn, Twitter and Facebook (Rapp et al., 2013). According to research from the USA, 97\% of consumers from the ages 16-24 are on Facebook, while $45 \%$ are on Twitter, 
$76 \%$ are on Instagram and $75 \%$ are on Snap Chat (Mitchell, 2012; NORC at the University of Chicago, 2017). With social media usage on the rise, television usage has begun to decline, as young people continue to spend less time watching television than any other adult group (Werbner, 2005).

\section{Message}

The appropriate message is needed to reach and resonate with the chosen audience. Once a channel is chosen, Noar (2012) states that a variety of different theories can be used to persuade individuals to think about what they are ultimately asked to do. Behavioral theory should be used to guide the message and appeal. Social marketers can consider various appeals when it comes to conveying a message to an audience, in this case, youth. There are strengths and limitations for each type of appeal, including fear appeals. For the purpose of this study, the Extended Parallel Process Model (EPPM) (Witte, 1992; 1998) will be used to analyze fear appeals messaging in campaigns targeting young people driving high.

Witte $(1992 ; 1998)$ posits that there are three central constructs in fear appeals: threat, fear and efficacy. Threat is an external stimulus and exists whether or not a person is aware of it. Fear is elicited through a threat and is a negative emotion accompanied by heightened arousal. Efficacy is an environmental message cue and can lead to an individual's belief of whether or not they can prevent the threat. A fear-based message must consider all three constructs to be effective.

To change behavior, Witte $(1992 ; 1998)$ explains the importance of threat and efficacy in terms of danger control and fear control. An effective fear-based campaign strives for danger control, and occurs when an individual has a high level of perceived threat and a high level of perceived efficacy. In this case, the individual is more likely to control and overcome the danger, as control processes dominate over fear processes. Conversely, fear control occurs when an individual has a high degree of perceived threat but a low degree of perceived efficacy. In this case, the individual responds to the fear instead of the danger, leading to denial or other maladaptive behaviors. Essentially, an effective fear-based message is one that drives both threat and efficacy.

The EPPM states that a fear appeal can be a successful method of changing behavior when a campaign offers easy to follow recommendations that allow the target audience an opportunity to avoid the threat (Cismaru, 2014; Witte, 1992; 1998). Five factors are theorized to trigger behavioral change and increase responsiveness, when utilized in a campaign. They are presented below in a drug driving context.

a) The first factor states that the undesirable outcome must be perceived as significant and harmful to the target audience (Witte, 1992; 1998). For drug driving, the audience should perceive that driving high is severe because it can cause an increase in crash rates, roadside fatalities or result in a criminal offense for the individual driving impaired. Severity is a key component when creating a fear appeal, as it underlies the remaining factors posited by in the EPPM to influence behavior change. 
b) The second factor states that the undesirable outcome can have a personal and direct effect on individuals and that the intended audience is vulnerable (Witte, 1992; 1998). For drug driving, the audience should perceive that drug driving can have a personal and direct negative effect such as causing an accident or being fined. Studies have demonstrated that those who have driven high are more likely to perceive drug driving as safe (McKiernan \& Fleming, 2017; StateFarm, 2017), therefore this perception needs to be addressed.

c) The third factor states that the audience should believe that the value of the recommended behavior outweighs the perceived costs or barriers of the undesirable outcome (Witte, 1992; 1998). Although recommended behaviors will always have an associated cost and inconvenience, these costs must be outweighed by the potential consequences of drug driving. Recommended behaviors may include take alternative means of transport such as a taxi or waiting for city transport. However, youth and young adults perceive these alternative options as having too great of barriers, such as wait time or monetary cost (Barrie et al., 2011). Currently, these perceived barriers of alternative means of transportation are prohibiting young drivers from seeking a safe ride home.

d) The fourth factor posited by EPPM to influence behavior change states that individuals must believe that they can follow the recommendations, therefore they must believe they can abstain from driving under the influence of drugs (self-efficacy) (Witte, 1992; 1998). While many individuals believe marijuana is not addictive like cocaine and other drugs, studies indicate that the euphoria induced by the THC has addictive properties. In fact, roughly $10 \%$ of individuals who try marijuana end up addicted (Helliker, 2006) or "cannabis dependent" (Roffman et al., 2006). These addictive properties might have a negative impact on the individual's self-efficacy. It is important for campaigns to provide easy to follow recommendations for their intended audience and address addiction where appropriate (Witte, 1992; 1998).

e) The fifth factor posited by the EPPM to influence the audience's willingness to adopt the recommended behavior in this case abstaining from driving high states that the individual should feel that following the recommendations would lead to the desired outcome (Witte, 1992; 1998). That is, taking a cab should feel effective in reducing the danger of drug driving or getting caught and punished by the police. Cismaru et al. (2009) argue that response efficacy is influential in changing an individual's behavior, but is often overlooked when designing campaigns.

An extended review of the EPPM since its introduction 20 years ago shows strong support for the model and for fear-based messages used in contemporary ad campaigns (Lewis et al., 2013; Roberto, 2013). Indeed, the EPPM (Witte 1992; 1998) has been tested across a variety of audiences (including young people), in different contexts (including safe driving), and using a variety of quantitative and qualitative methods (including surveys, content analysis, focus groups, and experiments) (Cismaru, 2014; Roberto, 2013). Having addressed the "message" part of the ACME framework, we now turn our attention to the "evaluation." 


\section{Evaluation}

Noar (2012) describes three types of evaluation, including formative evaluation, process evaluation, and outcome evaluation. Formative evaluation includes pre-testing initial campaign messages, researching audience channel preferences, and studying the behavior of interest. Process evaluation monitors the campaign for implementation and ensures an effective plan was put in place. Outcome evaluation determines if the behavioral change of attitudes and beliefs took place.

In addition, Manikam and Russell-Bennett (2016) in their social marketing theory-based approach for designing interventions, posit that using theory and learning from existent campaigns better guide development of future initiatives. Theory and research indicate specific constructs and issues that need to be communicated to promote behavior change. Therefore, in the next sections, existent initiatives against drug driving targeting youth are presented and analysed according to

the two theories found to promote behavior change (ACME and EPPM). Specific recommendations to enhance effectiveness are provided.

\section{Methodology}

\section{Search Criteria}

Following the methodology employed by Cismaru (2014) and Nelson et al. (2011), extensive Google and YouTube searches were conducted in July, August, and December of 2018 by two independent researchers to find relevant anti-marijuana campaigns targeted at youth and young adults. Keywords used included "Anti-marijuana campaign," "Youth and marijuana campaigns," "Youth and cannabis campaigns," "Marijuana advertisements," "Cannabis advertisements," "Social marketing marijuana," "Social marketing cannabis," "Marijuana and driving," "Cannabis and driving," "Drug Driving," "Driving high" and "Marijuana and the Extended Parallel Process Model." Using a snowball sampling approach, links were followed from the initially located websites to identify additional websites of interest. Government websites in countries where marijuana was legalized or decriminalized were also searched. Finally, relevant scholarly databases such as ABI-Inform and PsychInfo were searched to identify if the identified campaigns included supplementary materials such as campaign strategy reports and evaluative reports.

\section{Inclusion and Exclusion Criteria}

As in Nelson et al. (2011), several criteria were used to narrow the selection of initiatives for this study. First, the focus of the present study was on campaigns targeting youth and young adults. Second, campaigns were only included if they were in English. Campaigns were excluded if they were more than three years old at the time of the campaign search given the recent legalization of marijuana in Canada and parts of the USA; if they did not focus on the effects of driving high; or if they promoted the health benefits of medicinal marijuana. Single-channel 
campaigns were also excluded. Archived campaigns from websites of current campaigns were also excluded. Finally, campaigns strictly using blogs or linked websites as channels were excluded. Both multi-media and local media initiatives were included. Thirteen initiatives remained and are presented in Table 1.

\section{Content Analysis}

The campaigns were analysed based on the ACME framework (Noar, 2012) and the EPPM (Witte, 1992; 1998, 2013). All campaign components were considered and analysed as a whole. Analysis was based solely on the information found on the internet, put forth by the 13 campaign initiators. For instance, ads featuring a young male without additional description were categorized as targeting youth. Additionally, if the campaign was distributed across several channels, such as YouTube, radio and posters, it was categorized as a multi-channel campaign.

Following the methodology of Cismaru (2014), a table was created to include campaign title, web address and initiator, campaign objectives, target audience ("A" from ACME), campaign tools and materials ("C" from ACME), the variables posited by EPPM to promote behavior change (severity, vulnerability, self- and response efficacy and costs; "M" from ACME; see Table 1). Due to a low number of evaluative reports identified, evaluation was not included in the table. When a campaign's goal was to raise awareness regarding the dangers of driving high, only the campaign elements addressing driving high were analyzed to focus solely on research related to driving under the influence of cannabis.

Coding scheme for the EPPM variables were based on Cismaru et al. (2008), Nelson et al. (2011), and Witte (1992; 1998). For example, vulnerability refers to one's subjective perception of the risk of something negative happening to him or her. Questions crossing people's minds regarding perceived vulnerability include, "Am I at risk for this problem? How likely am I to get hurt?' Campaigns attempting to provide the answer to these kinds of questions in any way were considered to address vulnerability. Some examples are campaigns encouraging youth look for information, providing statistical/factual information, and trying to make people aware of their defenses. Following Nelson et al. (2011), two independent coders conducted the analysis. A third researcher merged the results and randomly checked the information. Disagreements were managed through discussion.

\section{Results}

Among the 13 campaigns included in the analysis, three were from Canada, five were from the United States, two from Australia, two from the UK, and one from New Zealand. The general goal of the analyzed campaigns was to raise the public's awareness on the dangers of driving high and reduce the incidence of driving high among young people. 


\section{ACME Findings}

\section{Audience}

While campaigns were chosen based on targeting young people, each campaign had its own approach for the audience as a whole (see Table 1). Some campaigns targeted young people as their sole audience ("Stoner Sloth", "Don't Drive High", "WEEDUI is Real"); others showed conversations between parents and children ("The Call That Comes After"), thus targeting youth and parents together. Many campaigns were targeted specifically at young males (i.e., "Come Down Before You Drive"). Several initiatives targeted the vast public by raising awareness on the overall risks of marijuana ("Youth and Impaired Driving"). To target youth, they provided subsequent links for youth to click on and learn more about how marijuana can specifically affect them and their ability to drive safely. Several campaigns, such as "Driving High = DUI" targeted everyone.

\section{Channel}

Most initiatives offered a multi-channel approach with extensive message mediums. These campaigns used a wide variety of channels such as radio ads, billboards, television ads, posters, YouTube videos, and social media channels such as Facebook, Twitter and Instagram. Some include Apps ("The Anti-Drug for Young Drivers"), 24 hours support phone line, and Live Chat ("Drugs and Driving Don't Mix"). Other campaigns only offered select channels of delivery, e.g., web page, posters or testimonials.

\section{Message and EPPM Findings}

Campaigns targeting youth driving high tend to use fear-based messaging. The variables posited by the EPPM to influence behavior change (i.e., severity, vulnerability, self-efficacy, response efficacy and costs) are addressed by many of the 13 analysed campaigns against drug driving targeting young people as illustrated below.

\section{a) Severity.}

All 13 campaigns addressed severity in different ways. Several campaigns, including "Drugged Driving What Will You Lose?," highlighted that the severity of the consequences were not worth the risk of driving high. For instance, "There's No Hiding Drug Driving," included a YouTube video outlining a young man losing his job, his license and getting a criminal record, all because he got caught driving high. Similarly, "Don't Drug Drive Think!," used the slogan "Another reason to be paranoid" and outlined the costs of driving high on their web page including legal consequences, job loss, increased car insurance, and difficulty getting in to other countries with a criminal record. "Drugged Driving What Will You Lose?" used videos depicting offenders in jail. 
In addition to using a legal approach, "WEEDUI is Real," used a variety of statistics to enforce the severity of the driving under the influence of drugs. It stated that "in the United States, 10.3 million people reported driving under the influence of drugs at least once during the past year" and that this rate was the highest among young adults aged 18-25. Other campaigns including "Come Down Before You Drive" used graphic content to address severity depicting serious accidents. Additionally, several initiatives including "Youth and Impaired Driving" shared testimonials and videos of families impacted by impaired driving. "Stoner Sloth" choose a unique approach and used humour to demonstrate the developmental delays of using marijuana in youth.

b) Vulnerability

Most of the campaigns analyzed addressed vulnerability with driving under the influence of marijuana. Different campaigns utilized different approaches to do so. For example, "WEEDUI is Real" uses the slogan "You can get a DUI for marijuana," highlighting the reality of a legal consequence happening to "You" specifically. In contrast, "Let's Talk Cannabis" highlights the vulnerability each person faces by taking marijuana in their FAQ and youth fact sheet. They stated that "cannabis and driving can lead to being caught when driving or operating any motorized vehicle." Other campaigns such as "Don't Drive High" addresses vulnerability with the slogan "Don't drive high, your life can change in an instant." "Come Down Before You Drive" addresses the fact that we are all vulnerable and have the capability of making mistakes, demonstrating that the negative consequences of driving high can happen to anyone.

While all campaigns addressed severity, not all campaigns addressed vulnerability. For instance, "Driving High=DUI" highlighted the legality of various substances, but did not emphasize that anyone could be at risk. Similarly, "Stoner Sloth" describes the potential stigma of being a 'stoner,' but did not point out that any audience member is vulnerable. These campaigns could further frame their messages to better resonate with their audience and make it feel more personal.

c) Recommendations to abstain from driving high and costs associated with the recommended behaviors.

Recommendations and their associated costs were addressed by some of the 13 campaigns. Most campaigns including "WEEDUI Is Real" provided recommendations such as having a designated driver, staying the night, using public transit, initiating conversations with family and children, calling a cab or friend, or booking a hotel room close to an event. "Drug Aware" encourages drivers to think about travel arrangements before going out, stay the night if it is not safe to drive, have a designated driver, have money for taxi/bus/train to go home, "look out for your mates", and "have a personal rule that you don't take drugs and drive, and that you don't go in a car with a driver who is on drugs" among others. Several campaigns seem to lack a clear recommendation. Since recommendations are thought to be critical to a successful campaign (Witte, 1992; 1998), a next step for these initiatives would be to depict individuals implementing the recommended action to avoid the consequences of driving high.

Among the recommendations, taking a cab, taking public transport or booking a hotel room all had monetary costs associated with them. Additional recommendations such as calling a friend, 
staying the night at a friend's house or planning a designated driver had minimal monetary costs but had potential social costs. Campaigns seldom attempt to directly reduce theses costs. One exception is "Drugged Driving, What Will You Lose?" which provided discount ride codes from Lyft, a campaign partner to reduce the cost of cab rides. Monetary and social costs still need to be addressed by the social marketer to relieve the perceived burden on the audience.

\section{d) Self-efficacy}

One campaign that provided a strong example of addressing self-efficacy was "The Call That Comes After." In addition to the interactive video that ends with a missed call and text from the child's parent, the website shows videos of youth watching these personal videos and having a positive response to the appeal. The campaign's recommendation was to have parents educate their children about driving high. Parents recommended that their children never get in the car with a stoned driver and instead take an alternate form of transport. Young people who took part in the interaction stated that they felt the all too real consequences of the campaign and felt the ability within themselves to abstain from driving high or ride in a car driven by a stoned driver.

\section{e) Response efficacy}

Several campaigns attempted to demonstrate response efficacy in different ways. For instance, "Stoner Sloth" showed that youth felt they could abstain from driving high in their evaluative report. In "The Call That Comes After" teens were interviewed and stated that they will no longer drive high after viewing the campaign. Additionally, online comments demonstrate that individuals are beginning to recognize the effects driving high can have on society. However, contention exists as individuals are polarized as to whether marijuana slows down reaction times making the driver unsafe, or whether driving slower while high makes the driver safer ("Don't Drive High"). Some campaigns emphasised how the legalisation of cannabis keeps driving high illegal (i.e., "Don't Drug Drive Think"). Most campaigns did not include response efficacy as a separate evaluative measure that must be used to capture the audience's reaction to each campaign.

\section{Evaluation}

A campaign evaluative report for "Stoner Sloth" was the only such report found online (Association for the Measurement and Evaluation of Communication [AMEC], 2016). According to this report, the campaign underwent pre-testing, but no details were described. As well, a postcampaign survey was conducted with 400 youth ages 14 to 18. Results showed that the campaign reached $60 \%$ of the target audience. Of those, $40 \%$ found the campaign to be credible, $32 \%$ said it 'potentially influenced their behaviour,' and the remaining group felt unaffected. The report had also revealed that public comments critiqued the campaign's credibility. Indeed, according media reports (Wahlquist, 2015), unbeknownst to the campaign authors, "Stoner Sloth" shared a name with a public cannabis selling site that was widely known by the general public. The site is known for its slogan "enjoy every smoking experience." Consequently, some people found the ads of the campaign to be "hilariously delightful," and they rejected the message and embraced Stoner Sloth. 
However, the evaluation report concluded that the comments were made by populations other than their target, and the criticisms therefore did not negatively affect the campaign's results. Indeed, it is important to remember that what can be funny to one audience may not be considered funny by another (Beard, 2008).

\section{Discussion}

The present analysis reveals that initiatives showed strengths and limitations in their execution. They had common goals of reducing the number of individuals that drive high and raising awareness about the dangers marijuana can have on driving. Several initiatives, "Don't Drive High", The Anti-Drug for Young Drivers", and "The Call That Comes After" consistently addressed each component in the EPPM. Others did due diligence in addressing severity, vulnerability, consequences, and recommendations to follow. However, they did not always seem to instill a sense of empowerment in the individual to take the recommended course of action. Therefore, in accordance to the EPPM, there is a need to continue to demonstrate easy to follow recommendations and increase coping mechanisms.

Most campaigns offered very similar recommendations: having a designated driver, waiting for a period of time, spending the night or taking public transportation. Some of these recommendations may be easier to follow than others. For example, public transport might be easier to obtain in a city than in a rural location. Other recommendations may require too much planning ahead, like booking a hotel or arranging to stay overnight at a friend's place. It is important for campaigns to provide realistic recommendations based on their audience.

Campaigns had difficulty demonstrating self-efficacy as many of the campaigns lacked encouraging slogans. Slogans often addressed severity and vulnerability i.e., "Your life can change in an instant," "You're worse on weed" and "More reasons to be paranoid," but did not include encouraging messages and positive courses of action. That is, campaigns can do more to make the recommended action feel possible to the audience. They may consider including slogans such as "Everyday people abstain from drug driving -you can be one of them!" (Cismaru et al., 2009).

Campaigns addressed response efficacy by highlighting the legal consequences of drug driving. Campaigns did not include success stories or statistics of people who made it home safe after choosing to drive sober. Showing positive statistics is known to increase the response efficacy of a campaign (Cismaru et al., 2009). Another way to increase response efficacy includes showing examples of individuals who followed the recommendation and achieved the desired outcome. For instance, an ad could show young people leaving a party where they smoked marijuana; some shared a taxi and they are home sleeping comfy in their beds, whereas other drove and caused an accident and are on the street, in the middle of the night, tired and stressed, with the police. Ultimately, legal, statistical or positive outcome-oriented campaigns are likely to increase response efficacy. Overall, applying theoretical frameworks such as ACME and EPPM as shown here can substantially increase the effectiveness of initiatives discouraging young people from driving high. 


\section{References}

Association for the Measurement and Evaluation of Communication [AMEC] (2016). The stoner sloth anti-cannabis campaign. Retrieved October 28, 2018 from https://amecorg.com/amecframework/assets/jm-stoner-sloth-case-study.pdf

Asbridge, M., Hayden, J. A., \& Cartwright, J. L. (2012). Acute cannabis consumption and motor vehicle collision risk: Systematic review of observational studies and meta-analysis. British Medical Journal, 34(1), 65-72.

Barrie, L. R., Jones, S. C., \& Wiese, E. (2011). At least I'm not drink-driving: Formative research for a social marketing campaign to reduce drug-driving among young drivers. Australasian Marketing Journal, 19(1), 71-75.

Beard, F. K. (2008). Advertising and audience offense: The role of intentional humor. Journal of Marketing Communications, 14(1), 1-17.

Berke, J., \& Gould, S. (2018). Canada has legalized marijuana — this map shows every US state that has legalized marijuana. Business Insider. Retrieved October 28, 2018 from https://www.businessinsider.com/legal-marijuana-states-2018-1

Bojkovsky, C., Childs, J., Callan, D., Hartner, G., Konescni, J., \& McNutt, K. (2017). Legalizing and Regulating Cannabis in Saskatchewan. Johnson Shoyama Graduate School of Public Policy, University of Regina. Retrieved October 28, 2018 from https://www.schoolofpublicpolicy.sk.ca/documents/research/reports/2017.11_JSGS_Can nabis\%20Report_FINAL.pdf

Cismaru, M. (2014). Using the extended parallel process model to understand texting while driving and guide communication campaigns against it. Social Marketing Quarterly, 20(1), 66-82.

Cismaru, M., Lavack, A. M., Hadjistavropoulos, H., \& Dorsch, K. D. (2008). Understanding health behavior: An integrated model for social marketers. Social Marketing Quarterly, 14(2), 2-32.

Cismaru, M., Lavack, A. M., \& Markewich, E. (2009). Social marketing campaigns aimed at preventing drunk driving. International Marketing Review, 26(3), 292-311.

Cismaru, M. \& Wuth, A. (2019). Identifying and analyzing social marketing initiatives using a theory-based approach. Journal of Social Marketing, 9(4), 357-397.

Fiala, S. C., Dilley, J. A., Firth, C. L., \& Maher, J. E. (2018). Exposure to marijuana marketing after legalization of retail sales: Oregonians' experiences. American Journal of Public Health, 108(1), 120-127.

Forrest, M. (2017). Legalized marijuana will lead to more impaired driving, police tell commons committee. National Post. Retrieved October 28, 2018 from https://nationalpost.com/news/politics/legalized-marijuana-will-lead-to-more-impaireddriving-police-tell-commons-committee

Hall, W. (2009). The adverse health effects of cannabis use: what are they, and what are their implications for policy? International Journal of Drug Policy, 20(6), 458-466.

Hall, W., \& Degenhardt, L. (2009). Adverse health effects of non-medical cannabis use. The Lancet, 374(1), 1383-1391. 
Handley, L. (2018). Los Angeles gets ready for cannabis truck advertising in 'largest marijuana marketing campaign.' CNBC. Retrieved October 28, 2018 from https://www.cnbc.com/2018/01/04/medmens-largest-marijuana-marketing-campaignhits-los-angeles.html

Helliker, K. (2006). As marijuana use rises, more people are seeking treatment for addiction. Wall Street Journal. Retrieved October 28, 2018 from https://www.wsj.com/articles/SB114652509054640879

Kushwaha, T. L. (2007). Essays on Multichannel Marketing, Ph.D. Dissertation, Texas A\&M University.

Lewis, I., Watson, B., \& White, K. M. (2013). Extending the explanatory utility of the EPPM beyond fear-based persuasion. Health Communication, 28(1), 84-98.

MacDonald, R., \& Rotermann, M. (2017). Experimental estimates of cannabis consumption in Canada, 1960 to 2015. Statistics Canada: Economic Analysis Division and Health Analysis Division. Retrieved October 28, 2018 from https://www150.statcan.gc.ca/n1/pub/11-626-x/11-626-x2017077-eng.htm

Manikam, S., \& Russell-Bennett, R. (2016). The social marketing theory-based (SMT) approach for designing interventions. Journal of Social Marketing, 6(1), 18-40.

Maxwell, J. C. (2012). Drunk versus drugged: How different are the drivers? Drug and Alcohol Dependence, 121(1-2), 68-72.

McKiernan, A., \& Fleming, K. (2017). Canadian Youth Perceptions on Cannabis. Canadian Centre on Substance Abuse. Ottawa, ON.

Migoya, D. (2017). Exclusive: Traffic fatalities linked to marijuana are up sharply in Colorado. Is legalization to blame? Denver Post. Retrieved October 28, 2018 from https://www.denverpost.com/2017/08/25/colorado-marijuana-traffic-fatalities/

Mitchell, L. (2012). The future of marketing according to youth: What 16-24s want from brands. The Guardian. Retrieved October 28, 2018 from https://www.theguardian.com/medianetwork/media-network-blog/2012/oct/25/future-marketing-youth

Mothers against Drunk Driving [MADD] (2018a). Cannabis and other drugs among drivers of highway vehicles dying within 30 days of a crash on a public road: Canada 2014.

Retrieved October 28, 2018 from https://madd.ca/pages/wpcontent/uploads/2018/05/Cannabis-and-Other-Drugs-Among-Drivers-Dying-Within-30Days-of-a-Crash2c-Canada2c-2014_April-2018.pdf

Mothers against Drunk Driving [MADD] (2018b). Youth and impaired driving. Retrieved October 28, 2018 from https://madd.ca/pages/impaired-driving/overview/youth-andimpaired-driving/

NORC at the University of Chicago (2017). New survey: Snapchat and Instagram are most popular social media platforms among American teens: Black teens are the most active on social media and messaging apps. Science Daily. Retrieved October 28, 2018 from www.sciencedaily.com/releases/2017/04/170421113306.htm

Nelson, K., Cismaru, M., Cismaru, R., \& Ono, T. (2011). Water management information campaigns and protection motivation theory. International Review on Public and Nonprofit Marketing, 8(2), 163-193. 
Noar, S. M. (2012). An audience-channel-message-evaluation (ACME) framework for health communication campaigns. Health Promotion Practice, 13(4), 481-488.

Rapp, A., Beitelspacher, L. S., Grewal, D., \& Hughes, D. E. (2013). Understanding social media effects across seller, retailer, and consumer interactions. Journal of the Academy of Marketing Science, 41(5), 547-566.

Roberto, A. J. (2013). Editor's note for the extended parallel process model: Two decades later. Health Communication, 28(1), 1-2.

Roffman, R. Stephens, R. S., \& Marlatt, G. A. (2006). Cannabis dependence: Its nature, consequences and treatment. Cambridge University Press.

Rose, R. L., Bearden, W. O., \& Manning, K. C. (2001). Attributions and conformity in illicit consumption: The mediating role of group attractiveness. Journal of Public Policy \& Marketing, 20(1), 84-92.

Royal Canadian Mounted Police [RCMP] (2018). Drug recognition expert evaluations. Retrieved October 28, 2018 from http://www.rcmp-grc.gc.ca/ts-sr/dree-eert-eng.htm

StateFarm (2017). Canadians who drive while high on marijuana believe they can do so safely. Retrieved October 28, 2018 from http://www.multivu.com/players/English/7835851state-farm-marijuanal

Statista (2018a). Daily time spent on social networking by internet users worldwide from 2012 to 2017 (in minutes). Retrieved October 28, 2018 from https://www.statista.com/statistics/433871/daily-social-media-usage-worldwide/

Statista (2018b). Spotify - statistics \& facts. Retrieved October 28, 2018 from https://www.statista.com/topics/2075/spotify/

Turnbull, D., \& Hodge Jr, J. G. (2017). Driving under the influence of marijuana laws and the public's health: Public health and the law. The Journal of Law, Medicine \& Ethics, 45(2), 280-283.

United Nations Office on Drugs and Crime [UNODC] (2015). The health and social effects of nonmedical cannabis use. Retrieved January 23, 2019 from https://www.who.int/substance_abuse/publications/cannabis_report/en/index 5.html

University of Victoria (2014). Drugs and driving: A review of the evidence. Centre for Addictions Research of British Columbia Retrieved October 28, 2018 from http://drugsanddriving.ca/

Valos, M. J. (2008). A qualitative study of multi-channel marketing performance measurement issues. Journal of Database Marketing \& Customer Strategy Management, 15(4), 239248.

Wahlquist, C. (2015). "Stoner sloth" anti-drug campaign gets reality check as medical experts walk away. The Guardian. Retrieved March 18, 2019 from https://www.theguardian.com/society/2015/dec/20/stoner-sloth-anti-drug-campaign-getsreality-check-as-medical-experts-walk-away

Werbner, D. (2005). Youth marketing; The billion dollar quest. Ad Media.

Witte, K. (1992). Putting the fear back into fear appeals: The extended parallel process model. Communication Monographs, 59(1), 329-349. 
Witte, K. (1998). Fear as motivator, fear as inhibitor: Using the extended parallel process model to explain fear appeals success and failures. In: P. A. Andersen and L.K. Guerrero (Eds.), Handbook of Communication and Emotion: Research, Theory, Applications, and Contexts. San Diego, CA, Academic Press, pp. 423-450.

Witte, K. (2013). Introduction: Pathways. Health Communication, 28(1), 3-4.

Wood, E., \& Salomonsen-Sautel, S. (2016). DUID prevalence in Colorado's DUI citations. Journal of Safety Research, 57(1), 33-38.

YOURS News (2015). Do youth in the US think legal marijuana and driving is safe? Youths for Road Safety. Retrieved October 28, 2018 from http://www.youthforroadsafety.org/newsblog/news-blog-item/t/do_youth_in_the_us_think_legal_marijuana_and_driving_is_safe 
Table 1: Campaigns, Objectives, and Components Adhering to the Audience, Channel, Message, Evaluation Framework (ACME) (Noar, 2012) and the Extended Parallel Process Model (EPPM) (Witte, 1992; 1998)

\begin{tabular}{|c|c|c|c|c|c|}
\hline \multicolumn{3}{|c|}{ Adherence to ACME } & \multicolumn{3}{|c|}{ Adherence to EPPM } \\
\hline $\begin{array}{l}\text { Campaign/Year/Initiator/Web } \\
\text { Address }\end{array}$ & $\begin{array}{l}\text { Objectives and Audience / Target } \\
\text { Group }\end{array}$ & $\begin{array}{l}\text { Channels / Campaign } \\
\text { Tools/Components }\end{array}$ & Threat / Severity and Vulnerability & $\begin{array}{l}\text { Coping/ Recommendations, } \\
\text { Costs and Self-Efficacy }\end{array}$ & Response-Efficacy \\
\hline 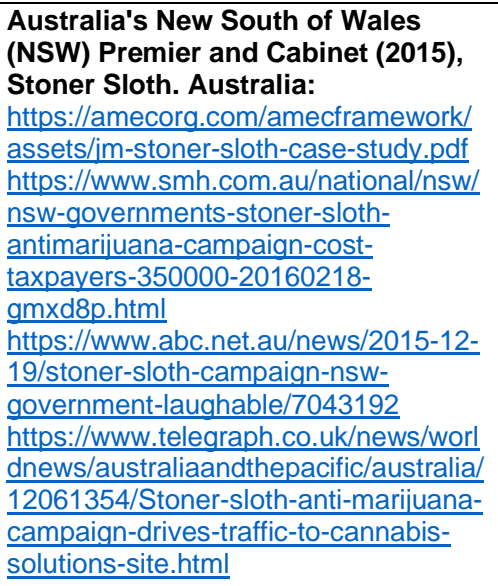 & $\begin{array}{l}\text { To prevent young individuals from } \\
\text { using marijuana at school, driving and } \\
\text { at parties. Targets Australian youth. }\end{array}$ & $\begin{array}{l}\text { YouTube, Facebook, } \\
\text { Instagram, Tumblr, } \\
\text { Website. } \\
\text { Digital platforms } \\
\text { Facebook } \\
\text { Videos } \\
\text { GIFs }\end{array}$ & $\begin{array}{l}\text { Addressed. Soft Approach. Not } \\
\text { entirely consistent with the EPPM. } \\
\text { Social consequences and youth } \\
\text { developmental delays highlighted. } \\
\text { Not mentioned in the strategy plan. }\end{array}$ & $\begin{array}{l}\text { Somewhat addressed. } \\
\text { Proposed no recommendations } \\
\text { and did not address any costs. } \\
\text { Evaluative report showed } \\
\text { respondents felt that the } \\
\text { campaign changed their } \\
\text { behavior, increasing self- } \\
\text { efficacy. } \\
\text { The idea is "empower young } \\
\text { people to abstain from using } \\
\text { Cannabis and to discourse their } \\
\text { friends and peers from using } \\
\text { Cannabis." } \\
\text { Not entirely consistent with the } \\
\text { EPPM. }\end{array}$ & $\begin{array}{l}\text { Addressed. } \\
\text { Campaign was } \\
\text { supported by youth as } \\
\text { per evaluative report. } \\
\text { Consistent with the } \\
\text { EPPM. According to } \\
\text { some, the campaign } \\
\text { failed. }\end{array}$ \\
\hline $\begin{array}{l}\text { California Department of Public } \\
\text { Health (2018), Let's Talk Cannabis. } \\
\text { USA: } \\
\text { https://www.cdph.ca.gov/Programs/DO } \\
\text { lletstalkcannabis/Pages/youth.aspx } \\
\text { https://www.cdph.ca.gov/Programs/DO } \\
\text { letstalkcannabis/CDPH\%20Document } \\
\text { \%20Library/October\%202017\%20Upd } \\
\text { ate/CDPH-YouthAndCannabis.pdf } \\
\text { https://twitter.com/CAPublicHealth } \\
\text { https://www.facebook.com/CAPublicH } \\
\text { ealth } \\
\text { ictps://www.youtube.com/user/CAPubl }\end{array}$ & $\begin{array}{l}\text { To begin the conversation with the } \\
\text { public outlining awareness and } \\
\text { knowledge about cannabis. Targets } \\
\text { the public of California; has a specific } \\
\text { youth section. }\end{array}$ & $\begin{array}{l}\text { YouTube, Facebook, } \\
\text { Twitter, Website, } \\
\text { Factsheet, FAQs. }\end{array}$ & $\begin{array}{l}\text { Addressed. High. Consistent with } \\
\text { the EPPM. Health risks of using } \\
\text { marijuana at a young age and its } \\
\text { impact on driving addressed. } \\
\text { "Caught in possession of cannabis } \\
\text { you will be required to complete } \\
\text { drug education or counseling and } \\
\text { community service." }\end{array}$ & $\begin{array}{l}\text { Somewhat addressed. Proposed } \\
\text { recommendations that were not } \\
\text { easy to follow such as "use } \\
\text { responsibly beyond the age of } \\
21 . " \text { Not entirely consistent with } \\
\text { the EPPM. }\end{array}$ & $\begin{array}{l}\text { Not specifically } \\
\text { addressed. Not } \\
\text { consistent with the } \\
\text { EPPM. }\end{array}$ \\
\hline $\begin{array}{l}\text { Colorado Department of } \\
\text { Transportation (2018), Drugged } \\
\text { Driving What Will You Lose? } 320 \\
\text { Movement. USA: } \\
\text { https://www.codot.gov/safety/alcohol- } \\
\text { and-impaired- } \\
\text { driving/druggeddriving/safety/alcohol- } \\
\text { and-impaired- } \\
\text { driving/druggeddriving/what-will-you- } \\
\text { lose-campaign }\end{array}$ & $\begin{array}{l}\text { To raise awareness and educate the } \\
\text { public on the dangers and laws } \\
\text { surrounding the legalization of } \\
\text { cannabis and driving under the } \\
\text { influence. Targeted Colorado } \\
\text { residents. Posters used young } \\
\text { people's photos, therefore it can be } \\
\text { considered that targets youth in } \\
\text { Colorado. }\end{array}$ & $\begin{array}{l}\text { YouTube, Facebook, } \\
\text { Twitter, Instagram, } \\
\text { Website, FAQs, Posters, } \\
\text { Radio and TV. }\end{array}$ & $\begin{array}{l}\text { Addressed. High. Direct approach. } \\
\text { Consistent with the EPPM. Legal } \\
\text { consequences and enforcement } \\
\text { addressed. Statistics used. } \\
\text { "In } 2015 \text {, Colorado enacted a new } \\
\text { law making an individual's fourth } \\
\text { DUI conviction automatically } \\
\text { eligible for a class } 4 \text { felony charge" }\end{array}$ & $\begin{array}{l}\text { Addressed. Recommended } \\
\text { taking a cab and provided } \\
\text { discount for Lyft (the " } 320 \\
\text { movement", a movement to plan } \\
\text { a ride home, before get high). } \\
\text { Easy to follow } \\
\text { recommendations; costs } \\
\text { addressed. Consistent with the } \\
\text { EPPM. }\end{array}$ & $\begin{array}{l}\text { Addressed. The drug } \\
\text { driving statistic shows } \\
\text { the improvement from } \\
2016 \text { to } 2017 \text {. }\end{array}$ \\
\hline
\end{tabular}


Davis and Cismaru

Community: The Anti-Drug (CTAD) (2016), For Young Drivers. USA:

https://communitytheantidrug.org/reso urces/youth-resources/for-youngdrivers-2/

\section{Drug Aware, Drugs and Driving
Don't Mix. Australia:}

https://drugaware.com.au/getting-the-

facts/

https://drugaware.com.au/about-

us/previous-campaigns/drug-

driving/\#nav-about-us\%20

Drug Free Kids Canada (2018), The Call That Comes After. Canada:

https://www.drugfreekidscanada.org/pr evention/drugs-and-driving/

\section{Government of Canada (2018), Don't} Drive High. Canada:

https://www.canada.ca/en/campaign/d on-t-drive-high.html

\section{Mothers Against Drunk Driving} (MADD) Canada (2018), Youth and Impaired Driving. Canada:

https://madd.ca/pages/impaired-

driving/overview/youth-and-impaireddriving/

https://madd.ca/pages/impaired-

driving/overview/cannabis-and-driving/ http://action.madd.ca/
YouTube, Facebook Twitter, Instagram, Posters, Testimonials, National Contests and bursaries.
To reduce the use of alcohol, marijuana, and other drugs among youth in the community. Targets people in Bannockburn, Deerfield, Highland Park, Highwood and

Riverwoods communities.
Twitter, Website, App. Online print, Brochure.

Addressed. High. Consistent with the EPPM. Provides safety data, accident rates, and costs of mpaired driving. Does not specifically outline vulnerability though, not consistent with the EPPM. "Vehicle crashes are the leading cause of death among young people aged 16 to 19 . In a study of driver deaths across six states, $28 \%$ of drivers tested tested positive for marijuana and $5 \%$ for opioids." Booklet, Wallet card, the EPPM. Legal consequences
To provide a framework of educational YouTube, Facebook, strategies designed to address illicit Twitter, Website, FAQs. drug use among youth in Western years old and general community. Press Ad, 24-hour support phone line, Live Chat.

YouTube, Facebook Twitter, Website,

o initiate the conversation between parents and children and prevent youth from driving high. Targets parents and youth and young adults in Canada.

Addressed. High. Consistent with addressed, health consequences addressed. "Drugs can seriously impair driving ability putting you at more risk of having a motor crash that can result in a fatality or serious injury."

Addressed. High. Consistent with the EPPM. Graphic content depicted. Used some facts and statistics showing legal, health, liability, life, and work outcomes.
YouTube, Facebook, Twitter, Website, Testimonials
To address consequences for youth driving high and educate them on how to choose a safe ride home. Targets Canadian youth and young adults.

Addressed. High. Consistent with the EPPM. Outlined seven major risks of driving high and included website testimonials.

"You could face consequences like a fine, criminal charges, even jail time" "Marijuana increases your chances of being in a crash."

To raise awareness and prevent driving. Targets youth in Canada.

Addressed. High. Consistent with the EPPM. Statistics and

testimonials used. positive for drugs. Of those, $12 \%$

"Young people have the highest rates of traffic death and injury per capita among all age groups and the highest death rate per kilomete driven among all drivers under 75 years of age. More 19-year-olds die or are seriously injured than
Addressed. Includes a "Ways to Stay Safe" section on website outlining preventative measures. Consistent with the EPPM. Self efficacy and costs are not addressed however. Not consistent with EPPM.

Recommendations include

"Agree on a code word or

symbol to text a parent or other adult to let them know you need a safe ride home."

Addressed. Staying safe page that provides checklist recommendations. 24/7 support line provided. Consistent with the EPPM, includes a "Your Life" page and examples of how each person responds differently to each drug.

Somewhat addressed. The organization developed a modern tool of communications allowing parents an easy way to begin an important conversation with their kids about the dangers of driving high. Somewhat consistent with the EPPM.

Addressed. Recommendations are easy to follow. Provided additional support and recommendations including how to get a ride home safely. Offered help for drug abuse, and encourage parents to start the conversation. Consistent with the EPPM.

Somewhat addressed. Includes a teen driving curfew where teens under the age of 18 have an invalid license after $10 \mathrm{pm}$. Somewhat consistent with the EPPM.

Not specifically addressed. Not consistent with the EPPM.

Addressed. In-depth interviews with teens showed them stating that they would not driv high. Consistent with the EPPM.

Addressed by showing comments on the website and by providing testimonials from people who have a driving high history. Consistent with the EPPM.

Addressed. Recommendations included signing a pledge not to drive high. Offered the youth and the young adults service and the "school assembly program." Somewhat easy to follow, low cost. Somewhat consistent with the EPPM.
Not specifically addressed. Not consistent with the EPPM. The website indicates that "Each year we offer our services to 20,000 victims/survivors across Canada." 
any other age group." Also,

showed the financial cost and

human cost of impaired driving.

New Zealand Transport Agency (2016), Come Down Before You

\section{Drive. New Zealand:}

https://www.nzta.govt.nz/safety/driving -safely/alcohol-and-drugs/drugaffected-driving-advertising/drug driving/

https://www.nzta.govt.nz/safety/driving -safely/alcohol-and-drugs/

\section{Road Safety Authority (RSA; 2017)} There's No Hiding Drug Driving. Ireland:

http://www.rsa.ie/RSA/Road-

Safety/Campaigns/Current-road-

safety-campaigns/Anti-Drug-Driving/

\section{Saskatchewan Government} Insurance (SGI; 2018), Driving High = DUI. Canada:

https://www.sgi.sk.ca/news?title=drivin g-high-is-a-dui

\section{United Kingdom (UK) Department of Transport (2018), Don't Drug Drive} Think! United Kingdom:

https://www.think.gov.uk/campaign/mo re-reason-to-be-paranoid/

https://www.think.gov.uk/campaign/bre athalyser-for-drugs/

\section{Ventura County Behavioral Health} (2018), WEEDUI is Real. USA:

http://venturacountylimits.org/en/preve ntion/impaired-driving/marijuana-anddriving
To raise awareness on acceptable times to wait before you drive in all neighborhoods. Targets New Zealand men in their early 30 s who smoke regularly with their mates and drive home shortly after.

To raise awareness on preliminary roadside drug detection. Targets male youth in Ireland. Twitter, SnapChat, Instagram, Website, TV Radio, Factsheet, Posters.

To raise awareness on the legal consequences of driving under the influence of drugs and to dispel the misconception that impairment only comes from one source. The campaign focuses on marijuana, prescription drugs and driving to make the roads safer. Targets all Saskatchewan drivers.

To raise awareness around new roadside swab. Targets young males in the UK.

YouTube, Twitter, Website, Radio, TV Posters.

To reduce DUls due to marijuana, prescription and over-the-counter drugs. Targets youth, specifically males in California.

cebook, Twitter, Website, Posters, Print,

YouTube, Facebook Twitter, Website, TV Radio, Billboard.

YouTube, Facebook, Twitter, Website, Factsheet, FAQs, Storytelling, Poster Addressed. High. Consistent with the EPPM. Graphic content depicted. "Research carried out by the Institute of Environmental Science and Research found that around one-quarter of all drivers and motorcyclists killed in road crashes were found to have

Addressed. High. Consistent with the EPPM. Legal consequences and social consequences addressed. "A study from the Coroners District in Kildare during 1998 and 2009 found that almost one in ten drivers killed had a positive toxicology for a drug or drugs."

Addressed. Moderate. Not entirely consisted with the EPPM.

Legal consequences addressed, statistics on webpage for acciden rates. "Impaired driving is against the law." "In 2016 in

Saskatchewan, 57 people were killed and 464 others were hurt in crashes involving alcohol or drugs."

Addressed. High. Consistent with the EPPM. Legal consequences and enforcement address minimum 12 month driving ban; criminal record; fine; prison time; endorsement on license or 11 years; job loss; shame; increase in insurance costs; trouble travel to some countries. Billboard.

Addressed. High. Consistent with the EPPM. Legal consequences addressed, statistics on webpage or local stats, enforcement

highlighted. "You can get a DUI fo cannabis present in their system. marijuana." " 1 in 12 of all fatally injured drivers tested positive for marijuana." "15,649 total fees plus Criminal record; Loss of driver's
Somewhat addressed. Recommendation included "Come down before you drive." Not easy to follow. Not entirely consistent with the EPPM.

Not addressed. Simply stated that roadside detection is available for cannabis. Not consistent with the EPPM.

Addressed. Recommendations include having a designated driver or calling a cab.

Straightforward, although does not address the costs associated with a cab. Generally consistent with the EPPM.

Somewhat addressed. Recommendation to discuss with your doctor if certain drugs are safe to drive. Not easy to follow. Not entirely consistent with the EPPM.

Not specifically addressed. Not consistent with the EPPM.

Not specifically addressed. Not consistent with the EPPM.

Not specifically addressed. Not consistent with the EPPM.

Addressed. Consistent with EPPM.

"In the decade that

followed the conception of THINK!, road deaths in the UK reduced by $46 \%$."

Addressed. Simple

recommendation of plan ahead and get a ride. Included a discount code on a safe ride home. Consistent with the EPPM.
Not specifically addressed. Not consistent with the EPPM. 
Davis and Cismaru

licence; 3+ year in jail possible, if anyone is injured." 